\title{
HUMAN FLOURISHING AND PHYSICAL SELF-CONCEPT IN PHYSICALLY ACTIVE WOMEN
}

\author{
Juan Antonio Moreno-Murcia, Elisa Huéscar Hernández, and Paulette Joseph \\ Sport Research Center, Miguel Hernández University, Elche, Spain
}

Original scientific paper

DOI: $10.26582 / \mathrm{k} .53 .1 .7$

\begin{abstract}
:
The aim was to identify the relationship between the physical self-concept profile and human flourishing in physically active women, including the validation of the human flourishing scale, which had not been validated yet in the Spanish context. Five hundred eighty $(\mathrm{N}=580)$ women, aged between 18 and 65 years $(\mathrm{M}=37.13$; $\mathrm{SD}=12.56$ years) completed the following questionnaires: Human Flourishing (FH), Physical Self-Perception Profile (PSPP), and Habitual Physical Activity in the last six months. After the structural regression analysis, we were able to demonstrate that the scale of human flourishing presented adequate psychometrics with a Cronbach's alpha of .83 and a CCI of .90. Through the cluster analysis we were able to present two self-concept profiles and the reliability indexes were satisfactory: the profile of high physical self-concept was higher in women with greater human flourishing $[\mathrm{F}(1,579)=11.75, \mathrm{p}<.001, \eta 2=.02]$ and higher levels of physical exercise $[\mathrm{F}(1,579)=11,19, \mathrm{p}<.001, \eta 2=.01]$ compared to the group with a low physical self-concept. We believe that these variables have a strong influence on the personal adjustment of women and should be addressed through preventive intervention for disorders related to an individual's distress.
\end{abstract}

Key words: health, gender, flourishing, physical activity, life satisfaction

\section{Introduction}

Although doing physical activity has been recommended for its benefits to health, there is still a high percentage within the female population that do not do any sport (CSD, 2010). Some interventions (Escanola \& Revuelta, 2009) have indicated that girls with low self-esteem and low self-concept can improve their self-esteem after a physical exercise program. According to Seligman (2014), due to an adjusted physical self-concept and generated subjective well-being, doing physical activity and sports could contribute to a more global perception of positive functioning in life of women, where positive emotions are higher than negative emotions (Fredrickson, 2009). Satisfaction or well-being has recently been related to human flourishing (Diener \& Robert, 2009; Seligman, 2014), which can be described as satisfaction for having accomplished one's aspirations and implies optimal psychological functioning (Diener \& Robert, 2009). So, the objective of the current study was to identify the relation between the physical self-concept profiles in women and regular physical activity and human flourishing.

This study is relevant to an international audience since knowledge about the association between physical and psychological variables can contribute to the design of programs for the prevention of health disorders, and thereby promote a higher quality of life for women.

\section{Self-concept in physically active women}

Diener, Suh, Lucas, and Smith (1999) point out that self-perceptions are the basis for a person's life satisfaction. To be exact, self-concept, which refers to the idea or opinion that each person has about him-/herself, is presented as one of the indicators of psychological health or personal adjustment (Esnaola, Goñi, \& Madariaga, 2008). This factor has been shown to have a positive relation with doing physical activity, and some studies (Ruíz de Azúa \& Rodríguez, 2005) about the relations between physical self-concept and physical activity have indicated that those who do physical activity regularly have better scores in all its dimensions.

The rates for doing physical exercises worldwide are higher in men than in women (García \& Llopis, 2011). In comparison to men, it seems that women do physical exercise largely for reasons of weight control or better physical image.

Bearing this in mind, it is necessary to carry out studies where new relations between these previous variables can be detected to help reveal the possible models of physical activity in women. 


\section{Well-being and physical state}

An individual's well-being is not only related to a balanced physical state, but also to a balanced psychological state, and a key to achieving this goal is to do physical activity. Women do physical activity for values related to: overcoming personal challenges, improving body image and health as well as socialization. In relation to socialization through physical activity, personal well-being appears to be an evaluative indicator (González-Serrano, Huéscar, \& Moreno-Murcia, 2013). In this line, knowledge about Positive Psychology (Seligman, 2002; 2014) has recently been applied to the sports environment (Blázquez, Corte, Días, \& Fonseca, 2009), resulting in a certain consensus among the current scientific community that physical exercise could favor how people regulate the emotional and cognitive aspects of their lives in all areas, enabling them to lead a full life (Videra-García \& Reigal-Garrido, 2013). These emotional and cognitive components define the concept of subjective well-being (Seligman, 2002, 2014). The cognitive component is represented by life satisfaction and well-being; it is defined as the extent to which a person positively evaluates the global quality of his/her experiences (Torregrosa, Belando, \& Moreno-Murcia, 2013).

\section{Well-being, satisfaction with life and human flourishing}

The recent study by Goñi, Esnaola, Rodríguez, and Camino (2015) points out that from adolescence to adulthood personal self-concept represents $46 \%$ of satisfaction with life. Satisfaction or well-being has recently been related to human flourishing (Diener \& Robert, 2009; Seligman, 2014), which can be described as satisfaction for having accomplished one's aspirations and implies optimal psychological functioning (Diener \& Robert, 2009). The key features of this construct include three elements from the theory of Authentic Happiness by Seligman (Seligman, 2002), and at least three to six additional features: self-esteem, optimism, resilience, vitality, self-determination and positive relations (Seligman, 2014). People who "flourish" not only feel well, but also do good, and so they obtain a positive global response from their environment. Both Fredrickson (2009) and Seligman (2014) talk of "human flourishing" to refer to functioning in life with positive levels of adaptation to all environments (personal, work, relations).

\section{Well-being in physically active women}

This concept could, therefore, enable us to identify the state of well-being in physically active women, since it reflects the extent to which a person experiences positive emotion, engagement, positive relations, and accomplishments in order to be able to finally experience some degree of satisfaction with life (Seligman, 2014). According to Seligman (2014), the main contribution of human flourishing, in contrast to the concept of life satisfaction, is that through an increase in its components and because they can be measured, we are able to stimulate flourishing in a person.

\section{This study}

In this sense and in view of the mentioned, women who regularly do physical activity and sports could have access to an experience of personal development characterized by their being able to make use of all their capabilities and to finally justify their immersion in the growth process of human flourishing. So, in this paper, we endeavored to identify the relation between the physical selfconcept profiles in women, regular physical activity and human flourishing. We hypothesized that women with high levels of physical self-concept would present high levels of human flourishing and high rates of physical exercise.

\section{Methods}

\section{Participants}

The sample consisted of 580 women who were doing any type of regular physical activity (zumba, pilates, bodypump, indoor cycling, bodybuilding, sailing, padel, toning, L.A.B, ballroom dancing, fitball, aerobics, body combat, aquagym, dancing, elliptical workout, running, tennis, pole dancing, hiking, skating, yoga, and swimming) at least on three days during a week. Their age was between 18 and 65 years $(\mathrm{M}=37.13 ; \mathrm{SD}=12.56)$. They were recruited from twelve sports centers in a large province of Spain. The sample was selected using random conglomerate sampling (Azorín \& Sánchez-Crespo, 1986).

\section{Measures}

Human Flourishing. We used the Flourishing Scale (FS) by Diener et al. (2009), which consisted of eight items and a single dimension describing important aspects of human functioning in relation to positive relations, feelings of competence and meaning attributed to life (e.g. "I lead a purposeful and meaningful life"), preceded by the phrase "How do I perceive my personal success?". Answers were given on a Likert scale from 1 (Totally disagree) to 7 (Totally agree).

Physical self-concept. We used the Spanish version of the Physical Self-Perception Profile (PSPP) developed by Fox and Corbin (1989), validated in the Spanish context by Moreno and Cervelló (2005). The questionnaire evaluates the following dimensions: physical condition (six items, e.g. "I always maintain an excellent physical 
condition and fitness"); appearance (eight items, e.g. "I find it difficult to maintain an attractive body"); perceived competence (six items, e.g. "I am good at nearly all sports"); strength (five items, e.g. "Compared with the majority of people of my sex, I believe I lack physical strength"); and self-esteem (five items, e.g. "I don't feel confident when participating in sports activities"). The test consisted of a total of 30 items and had the heading "When I do physical activity....". Answers were given on a Likert scale from 1 (Totally disagree) to 4 (Totally agree). Cronbach's alpha values were .69 for physical condition, .79 for appearance, .75 for perceived competence, .73 for strength, and .70 for self-esteem.

Regular physical activity. We used the Spanish version (Sarria, et al., 1987) of the Habitual Physical Activity Questionnaire by Baecke, Burema, and Frijters (1982) to measure perceived regular physical activity. Physical exercise in free time is evaluated using four questions. The first one refers to the type of sport or sports, the weekly frequency, and the number of months the activity was carried out. The result of this first question was calculated using the following formula: Modality (intensity $\times$ time $\times$ ratio) + Modality 2 (intensity $\times$ time $\times$ ratio). The different coefficients were used to calculate this formula, depending on the sport, the hours a week and the number of months it was carried out (Florindo \& Latorre, 2003). The other three questions evaluate the level of physical exercise in free time (e.g. "during my free time I do sport or physical exercises") using a Likert scale ranging from 1 (never) and 5 (very often). To calculate the result, the score from the first question was converted into values of 1 to 5 and the average was calculated for the four questions.

\section{Procedure}

We collected the information as follows. We contacted the people in charge of both public and private sports clubs (gyms, swimming pools, sports centers, etc.), to inform them about our objectives and request their collaboration. Afterwards, the participants were informed about the purpose of the research. Questionnaires were completed before and after different classes and supervised by the lead researcher, who answered any queries that arose. The questionnaires were answered individually and in an environment suitable for the women to be able to concentrate, taking about 20 minutes to complete. Participation was voluntary and anonymous. The items were explained to participants one by one to ensure they understood them, and the researcher described and explained the procedure for completing the questionnaire. All the participants' queries were answered, and no difficulties occurred in understanding any of the items.
As the human flourishing scale was not validated in the Spanish context, an inverse translation strategy was used (Hambleton, 1996). First, we translated the items into Spanish, then a group of translators translated the information into English again to check concurrence with the original version. Next, the battery of items was evaluated by three experts from this field (Lynn, 1986), who all estimated the pertinence of the items for measuring the constructs they had been created for, as well as their correct expression.

\section{Data analysis}

We calculated the descriptive statistics (averages, standard deviations, asymmetry and kurtosis values) for each of the items from the human flourishing scale. A confirmatory factor analysis was carried out and Cronbach's alpha was used to measure internal consistency to test the scale's validity and reliability. Different goodness of fit indices were used: $\chi^{2}, \chi^{2} / d$.f., CFI (Comparative Fit Index), IFI (Incremental Fit Index), RMSEA (Root Mean Square Error of Approximation) and SRMR (Standardized Root Mean Square Residual). The ratio between $\chi^{2}$ and degrees of freedom $\left(\chi^{2}\right)$ d.f.) was used because $\chi^{2}$ is very sensitive to sample size. For this indicator, values lower than five are usually acceptable (Bentler, 1990). According to $\mathrm{Hu}$ and Bentler (1990), the CFI and IFI values higher than .95 together with values equal to or lower than .06 for RMSEA and 0.8 for SRMR indicate a good fit of the model. The cluster analysis was carried out following the phases proposed by Hair, Anderson, Tatham, and Black (1998). First, different personality profiles were identified. This was done by dividing the sample randomly into two sub-samples. For the first sample, a hierarchical cluster analysis was made using the Ward method. Next, confirmation of the profiles found was carried out using cluster analysis with the second sample of women. A multivariate analysis of variance (MANOVA) was carried out to examine the characteristics of each variable. The analyses were made using the statistical software SPSS 21.0 and Amos 21.0.

\section{Results}

\section{Psychometric properties of the human flourishing scale}

An independent sample was used to validate the human flourishing scale (Annex 1). It consisted of 421 women who did regular physical activity (zumba, pilates, bodypump, indoor cycling, bodybuilding, sailing, padel, toning, L.A.B, ballroom dancing, fitball, aerobics, body combat, aquagym, dancing, elliptical training, running, tennis, pole dancing, hiking, skating, yoga, and swimming), aged between 18 and 72 years $(\mathrm{M}=35.85 ; \mathrm{SD}=.86)$, from twelve sports centers in a large province of Spain. 
Descriptive analysis of the scale items. Overall, the items presented a high score, which was close to the maximum for this scale, and standard deviation was close to 1 in all cases. The asymmetric and kurtosis values were within the ranges for a normal distribution of the data.

Confirmatory factor analysis. A confirmatory factor analysis was made based on seven measures observed in a latent construct. Since the result for Mardia's multivariate coefficient was 34.23, which indicated a lack of multivariate normality, the maximum verisimilitude method together with the bootstrapping procedure were used. The standardized regression weights ranged between .35 to .76. The indices obtained were adequate: $\chi^{2}(16$, $\mathrm{N}=421)=21.14, \mathrm{p}=.05 ; \chi^{2} /$ d.f. $=1.76 ; \mathrm{CFI}=.99$; $\mathrm{NFI}=.97 ; \mathrm{TLI}=.98 ; \mathrm{SRMR}=.02 ; \mathrm{RMSEA}=.04$.

Analysis of internal consistency and temporal stability. Internal consistency of the scale factors was calculated using Cronbach's alpha coefficient, and an alpha value of .83 was obtained. Temporal stability of the scale was analyzed using a sample of 56 participants, aged between 18 and 62 years $(\mathrm{M}=32.56 ; \mathrm{SD}=.76)$. These participants completed the scale on two separate occasions, with a period of four weeks between each time. The intra-class correlation coefficient (ICC) was calculated for the two times (pre- and pos-test). The average was $5.98(\mathrm{SD}=.93)$ and $6.01(\mathrm{SD}=.90)$ with an $\mathrm{ICC}$ of .91. Values of ICC between .70 and .80 indicate acceptable levels of stability; between .80 and .89 , moderate; and .90 or higher, high stability (Vincent, 1995).

\section{Descriptive analysis and correlation of all the variables}

The most valued physical self-concept variable was physical condition, followed by strength, appearance, perceived competence, and self-esteem. Scores of 5.90 and 6.51 were obtained for the human flourishing variable and regular physical exercise, respectively. All the variables correlated positively with each other, except for regular physical activity with appearance and self-esteem. (Table 1).

\section{Cluster analysis}

First, no lost cases were observed in any of the variables studied, so no has been excluded from the study sample. Secondly, all the variables were standardized using Z scores, with no scores above three being found, which implied the nonexistence of outlier classifications or lost cases in the whole sample. In the next step, the univariate distribution of all the grouped variables was examined for normality.

Sample 1 consisted of 290 women with an average age being 38.36 years $(\mathrm{SD}=12.85)$. In the first sample of women, an analysis of hierarchical conglomerates using the Ward method was made to identify the groups. The dendrogram obtained suggested there were two groups (Figure 1 and Table 2), a group where the women's scores for all

Annex. Scale of human flourishing

\begin{tabular}{|c|c|c|c|c|c|c|c|c|}
\hline & How do I perceive my personal success? & 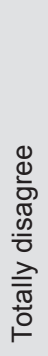 & 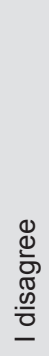 & 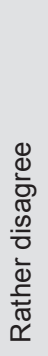 & 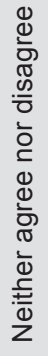 & 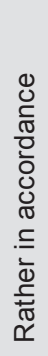 & 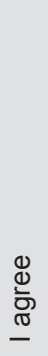 & 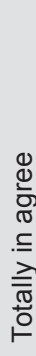 \\
\hline 1. & $\begin{array}{l}\text { The objectives I perceive in my life makes } \\
\text { sense to me. }\end{array}$ & (1) & 2 & 3 & 4 & 5 & 6 & (7) \\
\hline 2. & $\begin{array}{l}\text { I feel supported and gratified by those around } \\
\text { me. }\end{array}$ & (1) & 2 & 3 & 4 & 5 & 6 & ( \\
\hline 3. & $\begin{array}{l}\text { I am committed and interested in my daily } \\
\text { activities. }\end{array}$ & (1) & 2 & 3 & 4 & 5 & 6 & (7) \\
\hline 4. & $\begin{array}{l}\text { I actively contribute to happiness and welfare } \\
\text { of others. }\end{array}$ & (1) & 2 & 3 & 4 & 5 & 6 & (7) \\
\hline 5. & $\begin{array}{l}\text { I am competent and capable in activities that } \\
\text { are important to me. }\end{array}$ & (1) & 2 & 3 & 4 & 5 & 6 & $\boldsymbol{7}$ \\
\hline 6. & I am a good person. & (1) & 2 & 3 & 4 & 5 & 6 & $\theta$ \\
\hline 7. & I am optimistic about my future. & (1) & 2 & 3 & 4 & 5 & 6 & $\boldsymbol{7}$ \\
\hline 8. & People respect me. & (1) & 2 & 3 & 4 & 5 & 6 & $\theta$ \\
\hline
\end{tabular}


Table 1. Analysis of descriptive statistics and bivariate correlations

\begin{tabular}{lcccccccccc}
\hline Measures & $\mathrm{M}$ & $\mathrm{SD}$ & $\mathrm{R}$ & 1 & 2 & 3 & 4 & 5 & 6 & 7 \\
\hline 1. Strength & 2.59 & .45 & $1-4$ & - & $.26^{* *}$ & $.48^{* *}$ & $.24^{* *}$ & $.37^{* *}$ & $.11^{* *}$ & $12^{* *}$ \\
2. Physical condition & 2.78 & .57 & $1-4$ & - & - & $.50^{* *}$ & $.63^{* *}$ & $.37^{* *}$ & $.20^{* *}$ & $.22^{* *}$ \\
3. Appearance & 2.57 & .51 & $1-4$ & - & - & - & $.59^{* *}$ & $.64^{* *}$ & $.12^{* *}$ & .01 \\
4. Perceived competence & 2.57 & .60 & $1-4$ & - & - & - & - & $.40^{* *}$ & $.20^{* *}$ & $.17^{* *}$ \\
5. Self-esteem & 2.44 & .65 & $1-4$ & - & - & - & - & - & $.15^{* *}$ & .05 \\
6. Human flourishing & 5.92 & .83 & $1-7$ & - & - & - & - & - & - & $.16^{* *}$ \\
7. Habitual physical activity & 6.51 & .91 & - & - & - & - & - & - & - & - \\
\hline
\end{tabular}

Note. ${ }^{* *} p<.01$.

Table 2. Standardized values, means and standard deviations of the variables in each cluster group 1, group 2 and whole group

\begin{tabular}{|c|c|c|c|c|c|c|c|c|c|c|c|c|c|c|c|c|c|c|}
\hline \multirow{3}{*}{ Measures } & \multicolumn{6}{|c|}{ Sample 1} & \multicolumn{6}{|c|}{ Sample 2} & \multicolumn{6}{|c|}{ Whole Sample } \\
\hline & \multicolumn{3}{|c|}{$\begin{array}{l}\text { Cluster } 1 \\
(n=173)\end{array}$} & \multicolumn{3}{|c|}{$\begin{array}{l}\text { Cluster } 2 \\
(n=117)\end{array}$} & \multicolumn{3}{|c|}{$\begin{array}{l}\text { Cluster } 1 \\
(n=177)\end{array}$} & \multicolumn{3}{|c|}{$\begin{array}{l}\text { Cluster } 2 \\
(n=113)\end{array}$} & \multicolumn{3}{|c|}{$\begin{array}{l}\text { Cluster } 1 \\
(n=350)\end{array}$} & \multicolumn{3}{|c|}{$\begin{array}{l}\text { Cluster } 2 \\
(n=230)\end{array}$} \\
\hline & $M$ & $S D$ & $z$ & $M$ & $S D$ & $Z$ & $M$ & $S D$ & $z$ & $M$ & $S D$ & $Z$ & $M$ & $S D$ & $Z$ & $M$ & $S D$ & $Z$ \\
\hline 1. Physical condition & 2.47 & .42 & -.54 & 3.26 & .48 & .83 & 2.51 & .42 & -.47 & 3.20 & .46 & .72 & 2.49 & .73 & -.51 & 3.23 & .83 & .77 \\
\hline 2. Appearance & 2.31 & .30 & -.50 & 2.97 & .54 & .76 & 2.30 & .30 & -.51 & 2.98 & .48 & .78 & 2.31 & .58 & -.51 & 2.97 & .99 & .77 \\
\hline 3. Perceived competence & 2.28 & .39 & -.48 & 3.04 & .60 & .76 & 2.27 & .40 & -.49 & 3.02 & .57 & .73 & 2.27 & .65 & -.49 & 3.03 & .96 & .74 \\
\hline 4. Strength & 2.39 & .33 & -.44 & 2.91 & .42 & .69 & 2.36 & .34 & -.50 & 2.93 & .38 & .75 & 2.38 & .75 & -.47 & 2.92 & .89 & .72 \\
\hline 5. Self-esteem & 2.16 & .46 & -.43 & 2.82 & .74 & .58 & 2.21 & .45 & -.34 & 2.83 & .69 & .60 & 2.18 & .70 & -.38 & 2.83 & 1.09 & 1.09 \\
\hline
\end{tabular}

the variables of physical self-concept were high (cluster 2), and another group where the women's scores showed much lower averages for physical self-concept in all the dimensions (cluster1).

Sample 2 consisted of 290 women with an average age of 35.91 years $(\mathrm{SD}=12.17)$. The groups in the second sample of women were identified using the K-means test. The dendrogram obtained suggested there were two groups (Figure 2

and Table 3): a group where the scores for all the variables of physical self-concept were high (cluster 2), and another group where women showed much lower averages for physical self-concept in all the dimensions (cluster 1).

An analysis of hierarchical conglomerates using the Ward method was made to identify the groups

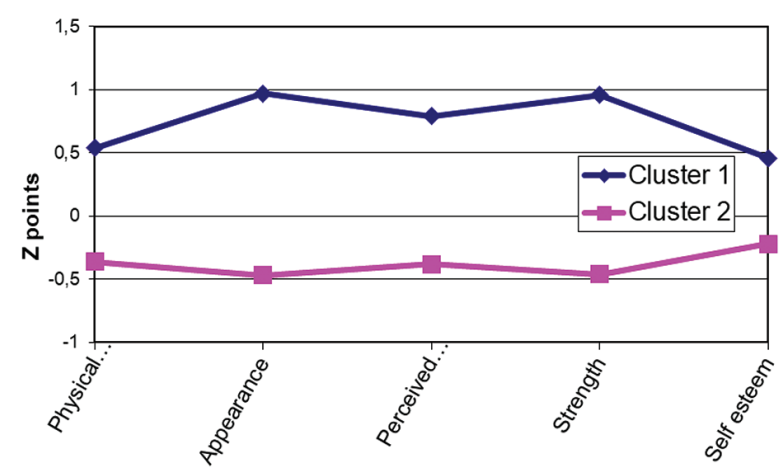

Figure 1. Hierarchical conglomerate analysis using the Ward method in sample 1. in the whole sample of women. The dendrogram obtained suggested there were two groups (Figure 3 and Table 3): one group called "high physical self-concept" (cluster 2) with high scores in all the dimensions, and another group called "low physical

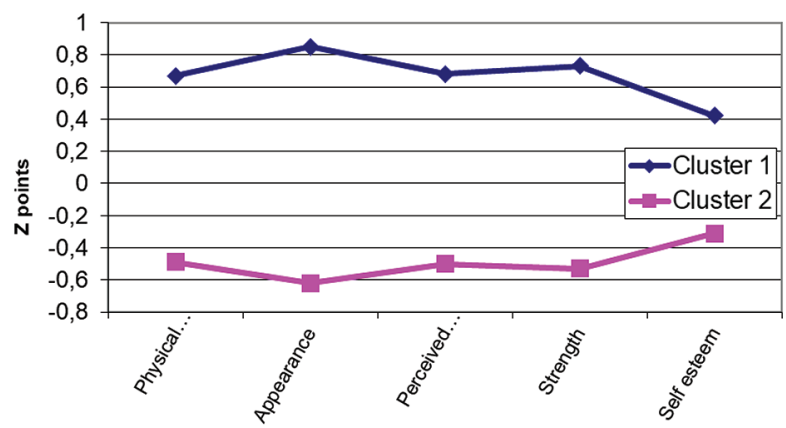

Figure 2. Cluster analysis-sample 2.

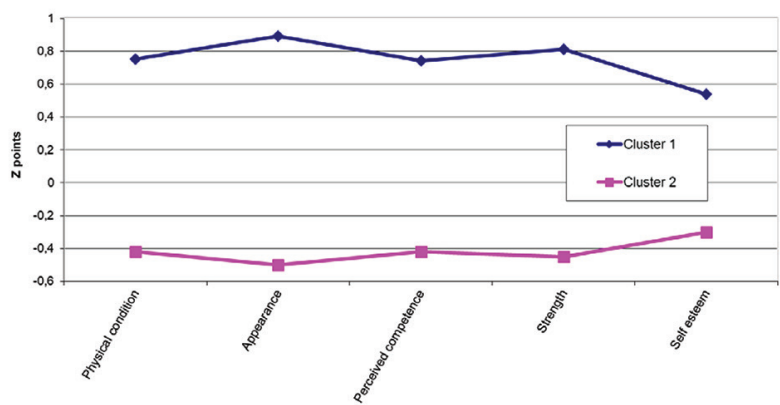

Figure 3. Hierarchical conglomerate analysis using the Ward method in the whole sample. 
Table 3. Differential analysis of human flourishing and habitual physical activity according to the cluster

\begin{tabular}{lccccccc}
\hline Measures & \multicolumn{2}{c}{$\begin{array}{c}\text { Cluster 1 } \\
(n=350)\end{array}$} & \multicolumn{3}{c}{$\begin{array}{c}\text { Cluster 2 } \\
(n=230)\end{array}$} \\
\hline & $M$ & $S D$ & $M$ & $S D$ & $F$ & $\eta^{2}$ \\
\hline 1. Human flourishing & 5.83 & .80 & 6.07 & .84 & $11.75^{* *}$ & .020 \\
2. Habitual physical activity & 6.41 & .94 & 6.67 & .84 & $11.19^{* *}$ & .019 \\
\hline
\end{tabular}

Note. ${ }^{* *} p<.01$.

self-concept" (cluster 1), with low scores in all the dimensions.

\section{Differential analysis}

To examine the characteristics of each physical self-concept profile from the whole sample, a multivariate analysis of variance (MANOVA) was made with the clusters as independent variables, and human flourishing and regular physical activity as dependent variables (Table 3 ). The results obtained showed differences [Wilks Lambda $=.94, F(10$, $569)=3.15, \mathrm{p}<.001, \eta 2=.05$ ] in favor of the "high physical self-concept" profile in human flourishing $[\mathrm{F}(1,579)=11.75, \mathrm{p}<.001, \eta 2=.02]$ and regular physical activity $[\mathrm{F}(1,579)=11,19, \mathrm{p}<.001, \eta 2$ $=.01]$.

\section{Discussion and conclusion}

In this study researchers aimed to test the relations between the possible physical self-concept profiles in a group of physically active women and doing physical activity and sports and human flourishing. The human flourishing scale was also validated in the Spanish context, representing the main methodological contribution of this study. The hypothesis that women who present a higher physical self-concept have higher values of human flourishing and higher rates of doing regular physical activity has been confirmed.

The data for the validation of the human flourishing scale were adequate, as were those obtained in the original study by Diener (2009). This is confirmed by the data from the confirmatory factor analysis and the data from internal consistency and temporal stability. The human flourishing variable contains eight items, which refer to how women feel supported by the people that surround them, their commitment to the activity, and whether the objectives they have set for their lives have been accomplished. Measurement is an important aspect of scientific research, and this instrument will contribute to providing an empirical explanation of the theoretical statements regarding human flourishment in women in the Spanish context. This will open the possibility to ratify this situation in new validation studies with other perspectives and experimental techniques. The validation of the human flourishing scale presented in this study, therefore, offers an instrument validated in Spanish and adapted to the context that characterizes 21st century societies. Its strengths being the sample scope, the age range, and the diversity in the types of physical activity that were addressed with respect to the participants.

As has been indicated some time ago, doing sport relates to a person's self-concept, and it is easier to intervene in physical self-concept than in general self-concept (Goñi, Ruíz, \& Rodríguez, 2004). To be exact, in this study the cluster analysis showed two profiles, one profile called high physical self-concept with high scores in all the dimensions, and another profile called low physical self-concept with lower scores in all the dimensions, coinciding with the data obtained in other studies (Esnaola, et al., 2008). This being the case, improvement in physical self-concept is related to the positive development of each of the dimensions. According to Allison, Dwyer, and Makin (1999), the strongest predictor for the improvement of physical selfconcept was sports competence. In the same line, research by Sonstroem, Harlow, and Josephs (1994) points out that self-efficacy in carrying out tasks facilitates an adequate interpretation of general physical self-evaluation.

The positive effects on self-esteem and selfconcept can also be due to the duration and frequency of doing physical activity and sport (Moreno-Murcia, Cervelló, \& Moreno, 2008). However, an increase in self-esteem through a positive change in physical self-concept is not automatically a result of the initial participation in physical activity programs but requires adherence to this activity. Nevertheless, these programs could be used to gradually improve women's perceptions of physical self-concept.

Finally, the most favorable perceptions of physical ability are seen to contribute to an increase in the levels of participation in physical activity and sports (Moreno-Murcia, et al., 2008). Some studies assert that people who do some type of physical activity or sport regularly show a higher interest in physical exercise and evaluate their physical fitness more positively than people who do no sport at all (Moreno \& Cervelló, 2005).

According to the above, doing physical activity and sport is seen as one of the factors related to an individual's physical and psychological well-being 
(González-Serrano, et al., 2013). In this sense, Escanola and Revuelta (2009) found that active people (those who do some type of physical activity more than two days a week) perceive themselves as better than inactive people in physical skills, physical condition, strength, general physical self-concept and general self-concept (MorenoMurcia, et al., 2015). Merino and Privado (2005) provide similar data, indicating that there are psychological resources which are fundamental to psychological well-being, and the physical and mental health of people. Optimism is not only associated with well-being, but it has also been observed to promote positive emotions which in turn promote the creation of solid resources leading to desirable results like health and longevity. Also, in a study by Reigal-Garrido, Becerra-Fernández, Hernández-Mendo, and Martín-Tamayo (2014) with a sample of adolescents, physical self-concept is the measure that best expressed physical condition in relation to the multi-dimensional self-concept, and significantly predicted the social, emotional and physical dimensions.

This study reveals the influence that the variables linked to physical condition have on these generic self-perceptions, and this should be adequately valued given the impact of interventions on personal self-concept, especially in physically active women (Moreno \& Cervelló, 2005). The development of feelings of accomplishment and belonging together with the development of new skills could contribute to increasing self-evaluations in appearance and physical ability of women, finally reinforcing their self-esteem (Corbin, 2002).

The latter argument leads us to extrapolate the relations found with human flourishing and establish its relation with physical exercise. In order for people, in this case women, to be able to perceive themselves as competent according to their physical condition, it is important that their perception of themselves is adjusted so that this adjustment can contribute to a personal growth that will provide human flourishing, that is to say, an optimal state of mental health, the fulfilment that comes from the balance between the factors of "feeling well and doing what I believe I should do". Therefore, this research suggests that physical activity should be encouraged in physically active women, which would in turn enable them to flourish.

We should not forget that this is a descriptive correlational study, so it is not possible to establish relations of causality. However, the information obtained can be of great use to sports technicians in understanding the physical self-concept profile in women and so to promote work on those dimensions where it is apparent physically active women have certain weaknesses. For this reason, more studies in this area are necessary to define any possible differences found. It would also be interesting for future research to design interventions directed at providing participants with a greater physical self-concept and human flourishing. Longitudinal studies would also be of interest as this could lead to finding out whether participants with a low physical self-concept profile and/or human flourishing are able to improve these profiles over time by following a physical exercise program with determined strategies (Moreno-Murcia, Huéscar, \& Hellín, 2014).

In conclusion, doing physical activity and sports in general involves a series of activities and elements that are present in the well-being and satisfaction of physically active women. These elements produce positive emotions that enable women to achieve the goals they have set themselves. In this context, self-concept, physical condition and the rate of physical activity have been drawn on to establish profiles which have allowed us to determine both the physical and psychological condition of women, with the result that the more adjusted profiles of physical self-concept were found in women with higher levels of physical exercise and with higher human flourishing.

For this reason, we believe that fostering competences necessary for human flourishing in physically active women can be addressed through focusing on adherence to physical activities and sports, and interventions in the adjustment of physical self-concept, which together would result in the improved well-being of women. 


\section{References}

Allison, K.R., Dwyer, J.J., \& Makin, S. (1999). Self-efficacy and participation in vigorous physical activity by high school students. Health Education and Behaviour, 26(1), 12-24. doi: 10.1177/109019819902600103

Azorín, F., \& Sánchez Crespo, J.L. (1986). Métodos y aplicaciones del muestreo. [Sampling methods and applications. In Spanish.] Madrid: Alianza Editorial.

Baecke, J.A., Burema, J., \& Frijters, J.E. (1982). A short questionnaire for the measurement of habitual physical activity in epidemiological studies. American Journal of Clinical Nutrition, 36, 936-942.

Blázquez, J., Corte, N., Días, C., \& Fonseca, A. (2009). Práctica deportiva y bienestar subjetivo: estudio con adolescentes portugueses. [Sports and subjective well-being: A study with Portuguese adolescents. In Portuguese.] Revista Iberoamericana de Psicología del Ejercicio Físico y el Deporte (RIPED). 4(1), 105-120.

Bentler, P. (1990). Comparative fix indexes in structural models. Psychological Bulleting, 107, 238-246.

Corbin, C. (2002). Physical activity for everyone: What every educator should know about promoting lifelong physical activity. Journal of Teaching in Physical Education, 21(2), 128-145.

CSD - Consejo Superior de Deportes. (2010). Encuesta sobre los hábitos deportivos en España 2010. [Survey of sports habits in Spain in 2010. In Spanish.] Madrid: CSD, Presidencia del Gobierno.

Diener, E. (2009). Subjective well-being. In E. Diener (Ed.), The science of well-being, Vol. 37 (pp. 11-58). New York: Springer.

Diener, E., \& Robert, C. (2009). New measure of well-being: Flourishing and positive and negative feelings. Social Indicators Research, 39, 247-266.

Diener, E., Suh, E.M., Lucas, R.E., \& Smith, H.L. (1999). Subjective well-being. Three decades of progress. Psychological Bulletin, 125(2), 276-302.

Diener, E., Wirtz, D., Tov, W., Kim-Prieto, C., Choi. D., Oishi, S., \& Biswas-Diener, R. (2009). New measures of well-being: Flourishing and positive and negative feelings. Social Indicators Research, 39, $247-266$. doi: 10.1007/978-90-481-2354-4_12

Esnaola, I., Goñi, A., \& Madariaga, J.M. (2008). El autoconcepto: perspectivas de investigación. [Self-concept: Perspectives research. In Spanish.] Revista de Psicodidactica, 13(1), 69-96.

Escanola, I., \& Revuelta, L. (2009). Relación entre la actividad física, autoconcepto físico, expectativa, valor percibido y dificultad percibida. [Relationship between physical activity, physical self, expectation, perceived value and perceived difficulty. In Spanish.] Acción Psicológica, 2, 31-43.

Florindo, A., \& Latorre, M. (2003). Validation and reliability of the Baecke questionnaire for the evaluation of habitual physical activity in adult men. Revista Brasileira de Medicina do Esporte, 9(3), 129-135. doi: 10.1590/S151786922003000300002

Fox, K.R., \& Corbin, C.B. (1989). The physical selfperception profile: Development and preliminary validation. Journal of Sport and Exercise Psychology, 11, 408-430.

Fredrickson, B. (2009). Positivity: Groundbreaking research reveals how to embrace the hidden strength of positive emotions, overcome negativity, and thrive. New York: Crown.

García, M., \& Llopis, R. (2011). Ideal democrático y bienestar personal: Encuesta sobre los hábitos deportivos en España 2010. [Ideal democratic and well-being: Survey on sporting habits in Spain 2010. In Spanish.] Madrid: Consejo Superior de Deportes y Centro de Investigaciones Sociológicas.

Goñi, A., Ruiz de Azúa, S., \& Rodríguez, A. (2004). Deporte y autoconcepto físico en la preadolescencia. [Sport and physical self in preadolescence. In Spanish.] Apunts: Educación Física y Deportes, 77, 18-24.

Goñi, E., Esnaola, I., Rodríguez, A., \& Camino, I. (2015). Personal self-concept and satisfaction with life in adolescence, youth and adulthood. Psicothema, 27(1), 52-58.

González-Serrano, G., Huéscar, E., \& Moreno-Murcia, J.A. (2013). Satisfacción con la vida y ejercicio físico. [Life satisfaction and physical exercise. In Spanish.] Motricidad. European Journal of Human Movement, 30, 131-151.

Hair, J.F., Anderson, R.E., Tatham, R.L., \& Black, W.C. (1998). Multivariate data analysis. New Jersey: Prentice-Hall.

Hambleton, R.K. (1996). Adaptación del tests para su uso en diferentes Idiomas y culturas: Fuentes de error, posibles soluciones y directrices prácticas. [Adaptation of tests for use in different languages and cultures: Sources of error, possible solutions and practical guidelines. In Spanish.] In J. Muñiz (Ed.), Psicometría (pp. 207-238). Madrid: Universitas.

Hu, L., \& Bentler, P.M. (1999). Cutoff criteria for fit indexes in covariance structure analysis: Conventional criteria versus new alternatives. Structural Equation Modeling, 6, 1-55. doi: 10.1080/10705519909540118

Lynn, M. (1986). Determination and quantification of content validity. Nursing Research, 35, 382-385. doi: 10.1097/00006199-198611000-00017

Merino, D., \& Privado, J. (2015). Positive Psychological Functioning. Evidence for a new construct and its measurement. Anales de psicología, 31(1), 45-54. doi: 10.6018/analesps.31.1.171081

Moreno, J.A., \& Cervelló, E. (2005). Physical self-perception in Spanish adolescents: Effects of gender and involvement in physical activity. Journal of Human Movement Studies, 48, 291-311. 
Moreno-Murcia. J.A., Cervelló, E., Martínez, C., Huéscar, E., \& Sáenz-López, P. (2015). Conceptions of ability and self-determined motivation in young Spanish athletes. Psychology/Psicologia Reflexão e Crítica, 27(3), $515-521$. doi: 10.1590/1678-7153.201427312

Moreno-Murcia, J.A., Cervelló, E., \& Moreno, R. (2008). Importancia de la práctica físico-deportiva y del género en el autoconcepto físico de los 9 a los 23 años. [Importance of physical-sport practice and gender in physical selfconcept of students aged 9 to 23 years. In Spanish.] International Journal of Clinical and Health Psychology. 8(1), 171-183.

Moreno-Murcia, J.A., Huéscar, E., \& Hellín, M. (2014). Mujer y deporte. Estrategias para su motivación. [Women and sport. Strategies for motivation. In Spanish.] Barcelona: Inde.

Reigal-Garrido, R., Becerra-Fernández, C., Hernández-Mendo, A., \& Martín-Tamayo, I. (2014). Relación del autoconcepto con la condición física y la composición corporal en una muestra de adolescentes. [Self-concept relationship with fitness and body composition in a sample of adolescents. In Spanish.] Anales de Psicología, 30(3), 1079-1085.

Ruiz de Azúa, S., \& Rodríguez, A. (2005). Autoconcepto físico y modalidad deportiva practicada. [Physical self and sport practiced. In Spanish.] In $\mathrm{M}^{\mathrm{a}}$ I. Fajardo, F. Vicente, A. Ventura, I. Ruiz \& J.A. del Barrio (Eds.), Nuevos contextos psicológicos y sociales en educación (pp. 513-529). Badajoz: Psicoex.

Sarria, A., Selles, H., Cañedo-Arguelles, L., Fleta, J., Blasco, M.J., \& Bueno, M. (1987). A self-test for quantifying physical activity in adolescents. Nutrición Clínica y Dietética Hospitalaria, 7, 56-61.

Seligman, M.E. (2002). Authentic happiness. New York: Free Press.

Seligman, M.E. (2014). Florecer: La nueva psicología positiva y la búsqueda del bienestar. [Flourish: The new positive psychology and the pursuit of happiness.] México D.F.: Océano.

Sontroem, R.J., Harlow, L.L., \& Josephs, L. (1994). Exercise and self-esteem: Validity of model expansion and exercise associations. Journal of Sport and Exercise Psychology, 16, 29-42.

Torregrosa, D., Belando, N., \& Moreno-Murcia, J.A. (2013). Predicción de la satisfacción con la vida en practicantes de ejercicio físico saludable. [Prediction of life satisfaction in practicing healthy exercise. In Spanish.] Cuadernos de Psicología del Deporte, 14(1), 117-122.

Vincent, J. (1994). Statistics in kinesiology. Champaign, IL: Human Kinetics.

Videra-García, A., \& Reigal-Garrido, R. (2013). Autoconcepto físico, percepción de salud y satisfacción vital en una muestra de adolescentes. [Physical self-perception of health and life satisfaction in a sample of adolescents. In Spanish.] Anales de Psicología, 29(1), 141-147.

Submitted: July 13, 2018

Accepted: February 8, 2021

Published Online First: April 12, 2021

Correspondence to:

Elisa Huéscar Hernández, Ph.D.

Health Psychology Department

Miguel Hernandez University, Elche, Spain

E-mail: ehuescar@umh.es 